\title{
Zygotic Drosophilia E-cadherin expression is required for processes of dynamic epithelial cell rearrangement in the Drosophila embryo
}

\author{
Tadashi Uemura, ${ }^{1}$ Hiroki Oda, ${ }^{1}$ Rachel Kraut, ${ }^{2,5}$ Shigeo Hayashi, ${ }^{3}$ Youhei Kataoka, ${ }^{1}$ \\ and Masatoshi Takeichi ${ }^{1,4}$ \\ ${ }^{1}$ Department of Biophysics, Faculty of Science, Kyoto University, Kitashirakawa, Sakyo-ku, Kyoto 606-01, Japan, ${ }^{2}$ Institut \\ für Entwicklungsbiologie, Universität zu Köln, D-50923, Köln, Germany; ${ }^{3}$ National Institute of Genetics, Mishima, \\ Shizuoka-ken 411, Japan
}

\begin{abstract}
Dynamic epithelial reorganization is essential for morphogenesis of various organs. In Drosophila embryos, for example, the Malpighian tubule is generated by cellular rearrangement of a preexisting epithelium and the tracheal network is formed by outgrowth, branching, and fusion of epithelial vesicles. Here we report that the previously identified locus shotgun (shg) encodes DE-cadherin, an epithelial cell-cell adhesion molecule of the classic cadherin type and that zygotic shg mutations rather specifically impair processes of the dynamic epithelial morphogenesis. In the mutants, the Malpighian tubule disintegrated into small spherical structures, and the tracheal network formation was blocked in selected steps. The malformation of these organs could be rescued by overexpression of $D E$-cadherin cDNA under a heat shock promoter. Unexpectedly, the zygotic null condition did not severely affect general epithelial organization; most epithelial tissues maintained not only their cell-cell associations but also their apicobasal polarity in the mutants. The zygotic null mutant retained a certain level of maternally derived $D E$-cadherin molecules until the end of embryogenesis. These results suggest that zygotic $D E$-cadherin expression is critical for the rearrangement processes of epithelial cells, whereas the maternally derived $D E$-cadherin may serve only for the maintenance of the static architecture of the epithelia.
\end{abstract}

[Key Words: DE-cadherin; tubulogenesis; cell rearrangement; Drosophila]

Received November 20, 1995; revised version accepted January 29, 1996.

Epithelial cells can reposition themselves without breaking the cell layer. This type of cellular rearrangement plays an important role in the production of tissues or organs of diverse morphology (for review, see Gumbiner 1992). A well-known example is amphibian gastrulation, in which a process of intercellular movement, called convergent extension, causes a dramatic elongation of the mesodermal tissue (Keller et al. 1992). In Drosophila embryos, a similar mechanism operates for morphogenesis of tubular organs. These include Malpighian tubules (MTs) and probably tracheal trees as well, both of which are of ectodermal origin and simple epithelial monolayers. MTs arise from the posterior region of the hindgut (for review, see Skaer 1992, 1993). Primordia of the tubules first grow out by cell divisions, and when the proliferation is complete, 12-14 cells encircle the lumen. Subsequently the cells start shifting

\footnotetext{
${ }^{4}$ Corresponding author.

${ }^{5}$ Present address: Institute of Molecular and Cell Biology, National University of Singapore, Singapore 0511, Malyasia.
}

their relative positions, generating elongated tracts with only two to three cells surrounding the lumen. Embryonic tracheal development is initiated by invagination of a cluster of cells in each of hemisegments T2 through A8 (for review, see Manning and Krasnow 1993). Each cluster gives rise to one metameric unit, which undergoes branching and outgrowth. Then a subset of branches fuses to one another to establish the basic framework. Once the invagination takes place, no further mitosis is observed, so this tracheal patterning most likely depends on cell rearrangement and/or cell shape change, although cellular mechanisms for individual branching processes have not been studied in detail.

In expectation of its possible functions in epithelial morphogenesis, we identified previously a Drosophila counterpart of the major vertebrate epithelial cadherin (E-cadherin) and designated it as DE-cadherin (Oda et al. 1994). The vertebrate E-cadherin belongs to a subgroup of the cadherin superfamily (for review, see Takeichi 1995). Members of this subfamily are named classic cadherins and they form multiprotein complexes with at 
least two classes of cytoplasmic molecules, $\alpha$-catenin and $\beta$-catenin. This assembly is essential for the cell adhesion activities of cadherins (Hirano et al. 1992; Kawanishi et al. 1994; Oyama et al. 1995). Besides having structural similarities between itself and the vertebrate classic cadherins, $D E$-cadherin was shown to mediate cell adhesion in vitro and bind catenins, $D \alpha$-catenin (Oda et al. 1993) and Armadillo (Arm), a $\beta$-catenin homolog (Peifer and Wieschaus 1990; McCrea et al. 1991). Arm was originally discovered as the product of a segment polarity gene belonging to the wingless (wg) class and is considered to have dual roles as an element of the adhesion apparatus and a transducer of the Wg signal reception (for review, see Hinck et al. 1994; Peifer 1995). DEcadherin is expressed in all embryonic ectodermal epithelia, subsets of neural and mesodermal cells, and endodermal cells (Oda et al. 1994; H. Oda, and T. Uemura, unpubl.). At boundaries between epithelial cells, $D E$-cadherin is localized at the position of the actinbased zonula adherens $(\mathrm{ZA})$; this suggests that $D \mathrm{E}$-cadherin is a component of $\mathrm{ZA}$, as is the case for the vertebrate E-cadherin (Tsukita et al. 1992; Tepass and Hartenstein 1994a). In invertebrates, three other molecules of the cadherin superfamily were reported: Fat (Mahoney et al. 1991), Dachsous (Clark et al. 1995), and the toxin receptor

BT- $R_{1}$ (Vadlamudi et al. 1995). However, their roles in cell adhesion remain to be investigated.

Vertebrate classic cadherins have been shown to be crucial for the integrity of polarized epithelial architecture (for review see Eaton and Simons 1995). This was demonstrated by a number of methods, including cDNA transfection of cell lines (McNeill et al. 1990; Watabe et al. 1994), expression of dominant-negative constructs (Kintner 1992; Levine et al. 1994; Hermiston and Gordon 1995; Lee and Gumbiner 1995), injection of antisense oligonucleotides (Heasman et al. 1994), and targeting of the mouse gene (Larue et al. 1994; Riethmacher et al. 1995). However, functions of cadherins in dynamic organogenesis have not been critically investigated in vivo by means of loss-of-function mutations. In this study we have isolated and characterized complete or partial lossof-function mutants of the $D E$-cadherin gene. Phenotypes of these mutants indicated that zygotic expression is crucial for processes of cell rearrangement, including the extension of MTs and tracheal tree patterning. Unexpectedly, these epithelial tissues did not dissociate into single cells in the zygotic null mutant, nor were most of the other epithelial organs so severely affected by the mutation.

\section{Results}

$\mathrm{DE}$-cadherin is encoded by shotgun

We cytologically located the $D E$-cadherin gene $|c a d E|$ very close to or in the chromosomal band 57B13-14. We found that two partially overlapping chromosomal deletions, $D f(2 R) D 17$ (O'Donnell et al. 1989) and $D f(2 R) E 2$ (Kraut and Campos-Ortega 1996), uncovered this gene (Fig. 1A). The transheterozygote of these two deficien-
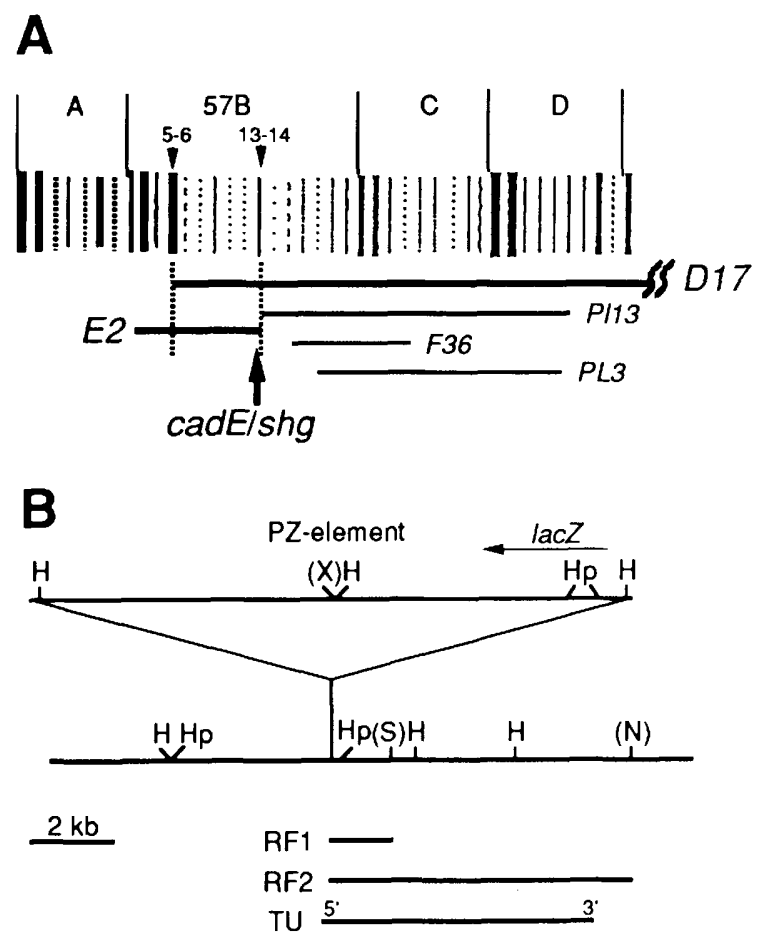

Figure 1. (A) Cytological map of $c a d E /$ shg and deficiency chromosomes. cadE/shg is located within the $57 \mathrm{~B}$ region on the second chromosome. Extents of deficiencies in individual lines are represented by solid lines. In a transheterozygote of $D f(2 R) E 2 / D f(2 R) D 17$ (E2/D17), the region of 57B5-6 to $13-14$ is deleted. This drawing of polytene chromosome bands is modified from that in O'Donnell et al. (1989). (B) Genomic map of the the $D \mathrm{E}$-cadherin gene $[(\mathrm{H})$ HindIII; $(\mathrm{Hp}) \mathrm{HpaI}]$. In the shg ${ }^{\text {P10469 }}$ chromosome, the PZ-element is inserted into the $5^{\prime}$-untranslated portion of the transcription unit (TU). RF1 and RF2 represent genomic regions of the plasmid rescue fragments. RF1 was rescued by $X b a \mathrm{I}(\mathrm{X})$ and SpeI $(\mathrm{S})$ digestion, and RF2 was isolated by $X b a I$ and $N h e I(N)$ digestion.

cies $(E 2 / D 17)$ thus represented a complete loss-of-function mutant for $c a d E$, and it was designated as the zygotic null mutant or simply null mutant in this study. Within that overlap interval, we mapped an embryonic lethal mutation, shotgun (shg), which had been isolated by mutant searches for aberrant cuticle patterns (Nüsslein-Volhard et al. 1984). As described below, we isolated a P-element allele of shg in which the transposon was inserted in the $D E$-cadherin gene. Furthermore, we could rescue shg phenotypes by $D E$-cadherin cDNA expression. Therefore, shg most likely encodes $D E$-cadherin.

Besides the null mutant, we studied three embryonic lethal shg alleles $\left(s h g^{2}, \operatorname{sh} g^{E 17 B}\right.$, and $\left.s h g^{S H N-1}\right)$, and one semilethal allele (shg ${ }^{\text {P10469, }}$, see Materials and methods). The embryonic lethal alleles were partial loss-of-function mutants; shg ${ }^{2}$ showed intermediate defects and shg ${ }^{E 17 B}$ and $s h g^{S H N-1}$ gave weaker phenotypes. The shg ${ }^{P 10469}$ had an insertion of a PZ element (Moldzik and Hiromi 1992) behind nucleotide 265 in the 5 '-untranslated region of the DE-cadherin cDNA (Fig. 1B). Revertant analyses confirmed that this insertion did cause a 
shg mutation: Of 32 independent revertant lines, 10 were completely viable both in a homozygous condition and in a trans relation to $\mathrm{shg}^{\text {P10469 }}$. Genomic Sourthern analyses indicated that the excision appeared to be precise in eight strains and near precise in 2 of the 10 strains (data not shown). The remaining 22 lines were homozygous lethal, and most of them produced embryos of weak shg phenotypes.

We immunostained mutant embryos for $D E$-cadherin. In ectodermal epithelia of the wild-type embryo, $D E$-cadherin was restricted to an apical position of cell-cell contacts, and its distribution was segregated from the territory of fasciclin III, a marker for the septate junction, which is located in the subapico-lateral region (Patel et al. 1987; Woods and Bryant 1993; see Fig. 2A). The $\operatorname{shg}^{E 17 B}$ (Fig. 2B), shg ${ }^{S H N-1}$, and $s h g^{P 10469}$ embryos exhibited normal apical distribution of $D E$-cadherin; but the signal intensity in the $\operatorname{shg}^{p 10469}$ homozygotes was slightly reduced compared to that in heterozygotes. Embryos of E2/D17 showed no intense immunostaining for DE-cadherin (Fig. 2C), although maternally derived molecules could be detected by Western analysis as described in the last section of this paper. In this null mutant, fasciclin III patterns were normal (Figs. 2E,F), suggesting little effect of this mutation on septate junction formation. $s h g^{2}$ showed an abnormal staining pattern for $D E$-cadherin; most signals were diffusely scattered in the cytoplasm although its apical concentration was also observed to some degree (Fig. 2D). Western analyses indicated that the $s h g^{2}$ mutant cadherin molecule was partly degraded in vivo (Fig. 8C, below). The $s h g^{2}$ product is probably mutated in such a way as to become more susceptible to proteolysis.

$D E$-cadherin is present in all epithelia in the normal embryo; therefore, extensive epithelial defects had been expected in the mutants. However, gross disorganization of epithelial tissues was limited to the head and ventral epidermis, Malpighian tubules, and tracheal ducts. In the null mutant embryo, ventral and head regions failed to form contiguous epidermis; its disruption became obvious at stage 11 , and most cuticles were missing in those regions at the end of embryogenesis (Fig. 3B). In the remaining ventral cuticle, some denticles were formed and they were flanked by naked regions. This pattern was not similar to that of a strong loss-of-function arm mutant that produced ectopic denticles at the expense of naked regions (Klingensmith et al. 1989). The cuticles of the $s h g^{2}$ mutant were similarly destroyed and tended to wrinkle. In $50 \%$ of the weak shg ${ }^{E 17 B}$ mutants, one or two small holes per embryo were seen in the cuticle (Fig. 3C). Mutant embryos of all the alleles showed defects in head involution and did not hatch, whereas no rupture was observed in their dorsal epidermis, as confirmed by staining for fasciclin III (Fig. 2F).
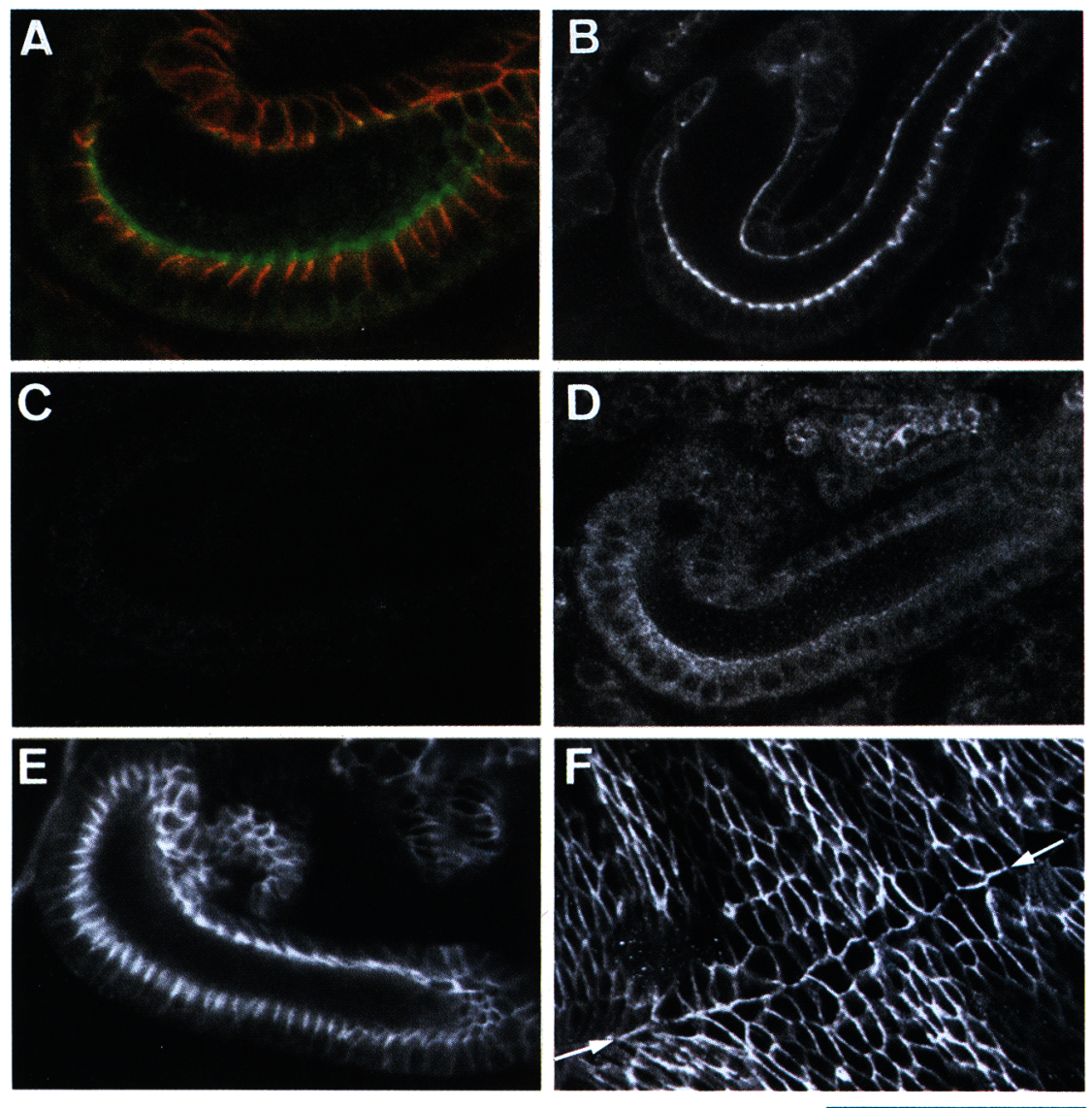

Figure 2. Subcellular localization of DEcadherin and fasciclin III in the deficiency and shg mutant embryos (stage 15). (A) A wild-type hindgut was double-labeled for $D E$-cadherin (green) and a marker for the septate junction, fasciclin III (red). $(B-D)$ $D E$-cadherin staining of hindguts in $\operatorname{shg}^{E 17 B}(B), E 2 / D 17|C|$, and $\operatorname{shg}^{2}(D)$. Confocal images were adjusted to increase brightness for $C$ and $D$ relative to $B .\{E, F\}$ Staining for fasciclin III in the hindgut $(E)$ and dorsal epidermis $(F)$ of the deficiency embryo. Note apparently normal distribution of fasciclin III in these tissues. Arrows in $F$ demarcate the dorsal midline. Scale bar, $30 \mu \mathrm{m}$ in $A$ and $50 \mu \mathrm{m}$ in $B-F$. 
Figure 3. Ventral cuticle patterns of the wild type $(A), E 2 / D 17(B)$, shg ${ }^{E 17 B}$ homozygote $(C)$, and heat-shocked E2/D17 carrying hsp-cadE transgene $(D)$. The deficiency embryo lacks most of the head and ventral cuticles $(B)$. Arrowheads in $B$ point to denticles generated, and the arrow in $C$ indicates a small hole. The $h s p-c a d E$ expression rescued the ventral cuticle phenotype, but head involution was still defective as shown by the exposed head skeleton (arrow). $(B-D)$ Composite pictures of different focal planes of the same embryos. Anterior is to the top. Scale bar, $100 \mu \mathrm{m}$.
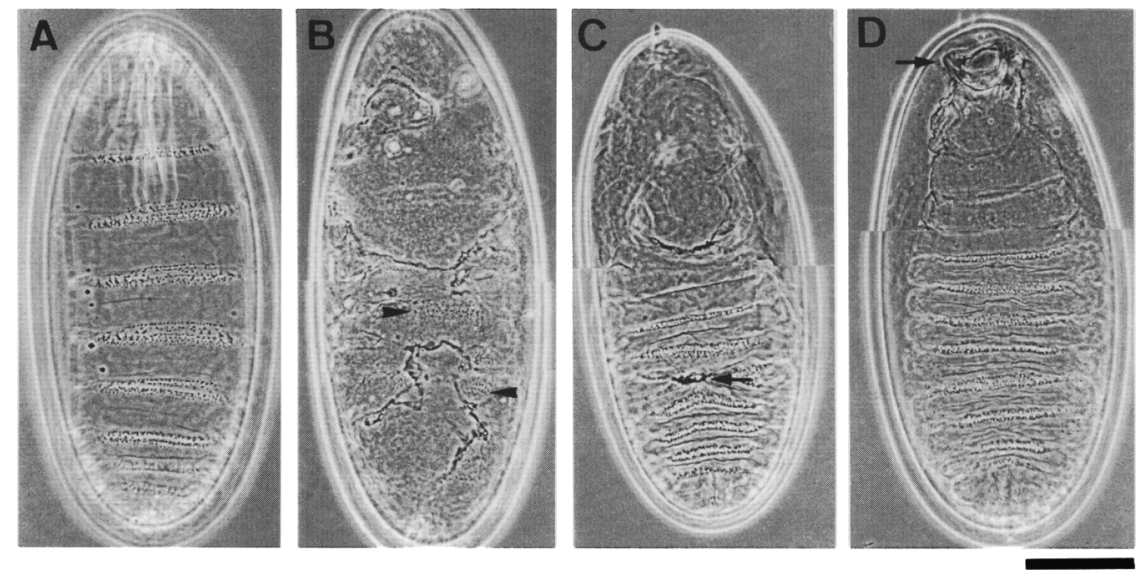

To study whether the mutant phenotypes could be rescued by $D E$-cadherin expression, we attempted expression of $D E$-cadherin cDNA under a heat shock promoter (hsp-cadE). In both the null and $s h g^{2}$ backgrounds, the cDNA expression restored the destroyed ventral cuticles, although the head defect was not recovered perfectly (Fig. 3D). In the following three sections, we focus on the phenotypes of MTs and tracheal ducts.

\section{Disruption of MTs in shg mutants}

The development of the MT is initiated by local evagination from the hindgut primordium (Skaer 1993). Following cell proliferation, cell rearrangement drives tubular elongation. Both mechanisms are regulated by specialized cells known as tip cells (Skaer 1989). As mentioned above, the MT structure was destroyed in the shg null mutant (Fig. 4B). However, the tip cells were present and differentiated into neurons in this mutant, as in the wild type (data not shown). We studied malformation of this organ by use of an antibody to a transmembrane protein, Crumbs (Crb), located at the outermost apical region of cell-cell boundaries as well as on the luminal surface (Tepass and Knust 1993; Wodarz et al. 1995). A structural abnormality of the MT was first detected at late stage 12 or early stage 13 , when the proliferation is still continuing in the wild type. At these stages, instead of having the slender MT morphology of the normal embryo (Fig. 4C), the MT of the null mutant was rounded (Fig. 4D) and the single-layered epithelium was locally kinked (Fig. 4E). When the mutant entered the initial stage of cell rearrangement (late stage 13), the tissues started falling apart and eventually disintegrated into small cell clumps (Fig. 4G), although they did not disperse into single cells even at stage 17. Each spherical structure was composed of several cells, and cells in the aggregate adhered to each other. Interestingly, the individual aggregate was a closed vesicle with $\mathrm{Crb}$ concentrated on its inner surface. Therefore, the MT cells appeared to preserve apical polarity.

Further evidence for the conservation of cell polarity was provided by monitoring intracellular distribution of a membrane cytoskeletal element, $\beta_{\text {Heavy }}$-spectrin (Thomas and Kiehart 1994). When embryos were fixed by heat methanol treatment (Miller et al. 1989), the cytoplasmic pool of $\beta_{\text {Heavy }}$-spectrin was washed away, resulting in an exclusive localization of the remaining molecules at an apical site of cell-cell contacts (Thomas and Kiehart 1994; as shown in Fig. 4H). In the mutant MT cell cysts, the $\beta_{\mathrm{Heavy}}$-spectrin-enriched domain was located inside the aggregates, as seen in the case of $\mathrm{Crb}$ staining (Fig. 4I, arrows).

At the end of embryogenesis, the MT cells secrete uric acid, which accumulates in the lumen and thus makes this organ visible under polarized light. The null mutant produced no trace of the tubular structure (Fig. 5B); as opposed to the wild-type, elongated tracts filled with the crystal (Fig. 5A). A small fraction $(\sim 10 \%)$ of $s h g^{2}$ embryos was able to generate short and discontinuous tubes (Fig. 5C). In the mutant embryos with the null or shg ${ }^{2}$ genetic background, the induction of $h s p-c a d E$ rescued the organism from the MT malformation; an example of a rescued $s h g^{2}$ is shown in Figure 5D.

\section{Defective outgrowth and fusion of tracheal branches in shg}

The shg mutation blocked specific steps of another tubulogenesis, that is, tracheal formation. To study fine structures of the tracheal network pattern, we used an antibody to an anonymous component that is deposited into the lumen (Klämbt et al. 1992). This staining allows detection of morphological changes of the trachea in each metamere unit, including its branching, outgrowth, and fusion (Fig. 6A,C,G). During development, the antibody first labels a subset of branches, the dorsal longitudinal trunks (DTs), just before their fusion at stage 13 (Fig. 6A). In the null mutant, DT cells started to migrate in the right direction, but the branch extensions were retarded (Fig. 6B). By the time DT fusion had already been completed in the wild-type embryo (Fig. 6C), $87 \%$ (91 of 105) of the mutant DTs still had not reached the more anterior metameres (Fig. 6D). Embryos with this "stall" phenotype could be rescued partially by the $D E$ - 

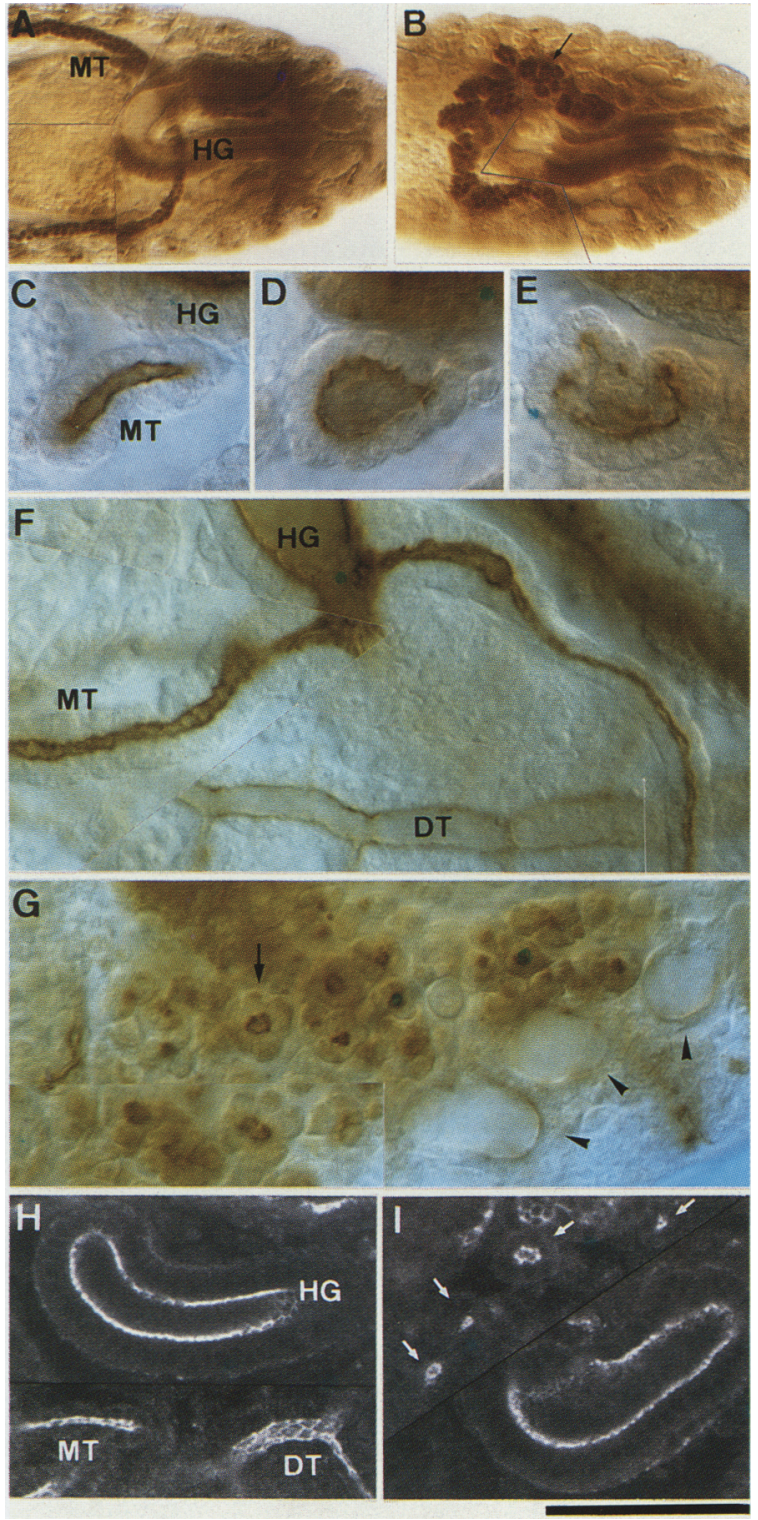

cadherin cDNA expression (Fig. 6E). In shg embryos, DTs fused partly, but the expansion of the tube diameter was arrested at every fusion point and the trunk remained constricted (Fig. 6F, arrows). This pattern was extreme in the weakest allele $\mathrm{sh}^{E .17 B}$, in which all of the DT joints exhibited the bottleneck shape (Fig. $6 \mathrm{H}$, arrows|. Connections between not only DTs but also lateral longitudinal trunks (LTs; Fig. 6C, arrowhead) were hindered in these mutants. LT interconnection was finished before stage 16 in the wild type (Fig. 6G, arrowhead). However, even at stage 16 , no LT fusion took place in the null mutant and $40 \%(38 / 96)$ of the LTs were not linked in the $s h g^{E 17 B}$ embryo (Fig. $6 \mathrm{H}$, aster-
Figure 4. Disintegrated malpighian tubules (MTs) in the deficiency embryo. $(A, B)$ Dorsal views of the wild-type $(A)$ and the $E 2 / D 17(B)$ embryos at stage 15 . Nuclei of MTs were visualized with an enhancer trap marker A154 (Bellen et al. 1989). In the mutant, the tract was converted into discontinuous cell aggregates (arrow). (HG) Hindgut. (C-G) Immunostaining of wildtype $(C, F)$ and deficiency $(D, E, G)$ embryos with anti-Crb antibody. $(C, D)$ Dorsal views of stage 13 embryos. $(E)$ A dorsolateral view of a deficiency embryo slightly older than that in $D . \mid F, G)$ Dorsolateral views of late stage 15 embryos. In the mutant, cells of the MT formed spherical structures with a polarized Crb distribution (arrow). Elements of the dorsal longitudinal trunk (DT) of the tracheal system contacted each other, but they were not interconnected (arrowheads). $\{H, I\rangle$ Distribution of $\beta_{\text {Heavy }}{ }^{-}$ spectrin in the wild-type $(H)$ and the deficiency embryos $\langle I\rangle$ fixed by the heat methanol method. Dorsal views of stage $15 \mathrm{em}-$ bryos. $\beta_{\text {Heavy }}$-spectrin is located at the apical pole of cell-cell boundaries. In the deficiency embryo, $\beta_{\text {Heavy }}$-spectrin was concentrated on inner faces of cysts derived from disrupted MTs (arrows). The staining pattern in the hindgut was not altered. $\{A, B, F, G, H, I\}$ Composite pictures of different focal planes. Anterior is to the left. Scale bar, $135 \mu \mathrm{m}$ in $A$ and $B, 35 \mu \mathrm{m}$ in $C-G$, and $50 \mu \mathrm{m}$ in $H$ and $I$.

isks). On the other hand, shg mutations did not essentially affect other aspects of tubular elongation. Every mutant metamere unit gave off shoots in the dorsoventral direction as well as visceral branches (Fig. 6C,D, arrow), although some of these tubes occasionally generated discontinuous points (Fig. 6F, asterisks).

Like developing MTs, the blind ends of outgrowing tracheal branches are associated with tip cells (Manning and Krasnow 1993). One class of the tip cells is termed homotip, and these are the leading cells of certain branches like DTs and LTs. We found that an antibody to the gene product of escargot (esg) stained nuclei of these homotip cells (Fuse et al. 1994) (Fig. 6I). Although roles of the tip cells in tracheal development have not been established, physical interactions between them precede the fusion (Manning and Krasnow 1993; S. Hayashi, unpubl.). In the shg null mutant, we could detect cells expressing esg as in the wild type (Fig. 6J), indicating that this mutation had no effect on tip cell differentiation.

\section{Tracheal branching patterns in arm and wg mutants}

As cadherin function requires $\beta$-catenin (Kawanishi et al. 1994; Oyama et al. 1995), we examined tracheal patterning phenotypes in mutants of arm, which encodes a Drosophila $\beta$-catenin (Peifer and Wieschaus 1990; McCrea et al. 1991). Tracheal phenotypes of arm were similar, though not identical, to those of shg (Figs. 7A-C). In

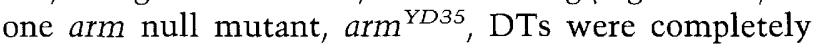
missing and LTs did not link to each other at all (Fig. $7 \mathrm{~A}, \mathrm{~B} \mid$. In an arm hypomorph, arm ${ }^{H 8.6}$, DTs exhibited irregular width, and the connections between LTs were incomplete (Fig. 7C). We also attempted to determine whether the role of Arm in tracheal development is dependent on the signaling molecule $\mathrm{Wg}$, as Arm is known to function downstream of $\mathrm{Wg}$ in the pattern formation of segment polarity (Noordermeer et al. 1994; Peifer et 

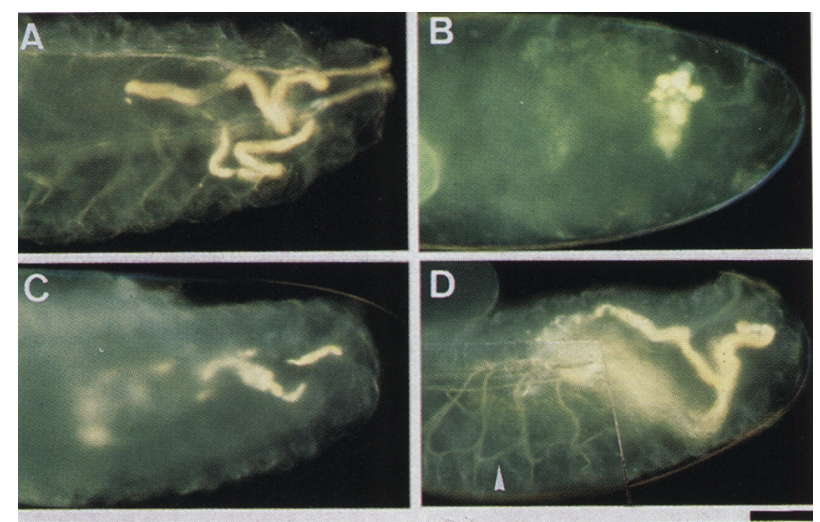

Figure 5. Structures of MTs in shg mutants and a phenotypic rescue by $D E$-cadherin cDNA expression. MTs at the end of embryogenesis or in first-instar larvae were observed under polarized light. $(A)$ Wild type; $(B) E 2 / D 17$ did not display any tubular organization; $(C)$ generation of short tracts in a shg ${ }^{2}$ homozygote $;(D)$ heat shock-treated $s g^{2}$ embryo that had the hspcadE transgene. The induction of $D E$-cadherin rescued both MTs and a tracheal network (arrowhead). The recovered tracheal branches at this stage are visible if filled with gas. In $A$, tracheal trees were out of focus. $D$ is a composite panel of two different focal planes. All embryos are oriented with anterior to the left and dorsal down. Scale bar, $50 \mu \mathrm{m}$.

al. 1994; Siegfried et al. 1994). In contrast to the indistinguishable ventral cuticle patterns in the arm and $w g$ mutants, tracheal defects were quite different between these two mutant embryos. In a wg null mutant, $w g^{C X 4}$, the entire dorsolateral ectoderm shows a transformation toward tracheal cells, but most of them do not invaginate and remain at the surface (Fig. 7D star; P. Green and V. Hartenstein, pers. comm.). DT-like branches were, however, formed partially on each side of the body (Fig. 7D, arrow), indicating that DT formation does not depend on wg activity completely. Therefore, the role of Arm in tracheal morphogenesis is at least partly separate from that of $\mathrm{Wg}$. Although the tracheal system was defective in both shg and arm mutants, MTs extended normally without any breakage in $\mathrm{arm}^{Y D 35}$.

\section{Maternally derived $\mathrm{DE}$-cadherin and catenins in the shg zygotic null mutant}

In shg mutants, severe destruction was not seen in epithelial organs of the intestinal tract other than the MT. Invaginations of the salivary gland, forgut, and hindgut primordia proceeded normally, and their epithelial monolayers were not torn, at least at a gross level. The null mutants developed an esophagus and proventriculus from the forgut primordia as in the wild type, although their shape was slightly distorted. All of these ectodermal epithelia showed typical apical distributions of both $\mathrm{Crb}$ and $\beta_{\text {Heavy }}$-spectrin (for $\beta_{\mathrm{Heavy}}$-spectrin, see Fig. 4I).

In an attempt to understand why severe phenotypes were limited to particular organs, we studied whether the zygotic null mutant produced $D E$-cadherin proteins from maternal transcripts. Unhatched embryos (22-26 hr at $25^{\circ} \mathrm{C}$ after egg laying/ of $E 2 / D 17$ were selected on the basis of their morphological features, and levels of $D E$-cadherin and catenins were compared to those of the wild type, which had two copies of shg $^{+}$(Fig. 8A). The E2/D17 embryos of this age contained nearly $20 \%$ of the wild-type level of $D E$-cadherin protein expression. This abundance was confirmed in embryos homozygous for $D f(2 R) D 17$ (Fig. 8B). These embryos were selectable at earlier stages (13-16 hr) because their whole morphology was in disarray. In immunostaining for $D E$-cadherin, the mutant embryos stained less brightly than wild-type siblings at stage 8 , and they did not give signals at cell-cell junctions except for weak ones in the amnioserosa at stage 13. At later stages, no signals were obtained at cellular boundaries throughout the embryos (Fig. 2C). Thus, despite the presence of a certain level of maternally derived $D E$-cadherin, we could not clearly detect them at cell-cell contact sites within the range of the sensitivity of immunohistology.

The zygotic removal of $D E$-cadherin expression also reduced the expression of $\beta$-catenin. Two forms of Arm/ $\beta$-catenin are generated by alternative splicing (J. Loureiro and M. Peifer, pers. comm.). The larger isoform, which is thought to be involved in Wg signaling, is predominantly associated with $D E$-cadherin /Oda et al. 1994). Western blot analysis showed that the shg null mutation dramatically decreased the level of this large form (Fig. 8A,B, arrow). In sharp contrast, the amount of the smaller neural-specific isoform was not altered (Fig. $8 \mathrm{~A}, \mathrm{~B}$, arrowhead). As for $D \alpha$-catenin, only a slight decrease in its total level was observed (Fig. $8 \mathrm{~A}, \mathrm{~B}$ ). This would be at least partly attributable to the strong expression of $D \alpha$-catenin in axon tracks that were not affected by shg mutations (see below).

Images of embryos immunostained for Arm were consistent with the results of the Western analyses (Fig. 9AD). In the wild-type embryo, in addition to the ubiquitous expression of membrane-associated Arm molecules, cells that received the $\mathrm{Wg}$ signal also accumulated Arm in the cytoplasm (Peifer et al. 1994), generating the wellknown Arm transversal stripes (Fig. 9A). The shg null embryo displayed the normal Arm stripes until stage 9, but signals at both the stripes and interstripe regions started to decay at stage 10 (Fig. 9B). This alteration of the Arm patterns did not appear to affect epidermal cell fates, as shown by denticle patterns (Fig. 3B). In epithelial tissues of the wild-type embryo at later developmental stages, the apical zone of cell-cell boundaries (Fig. 9C), where ZA develops, was enriched with Arm (Peifer 1993). However, in every shg mutant embryo, these signals of Arm were greatly weakened not only in MTs and trachea but also in all the other epithelia (Fig. 9D). We could not detect any organized arrays of staining signals along intercellular junctions for $D \alpha$-catenin either (Fig. $9 \mathrm{E}, \mathrm{F})$. Finally, the central nervous system (CNS) in the mutant embryo exhibited intense immunostaining signals for both $D \alpha$-catenin and Arm, as in the wild type. Images for $D \alpha$-catenin staining are shown in Figure 9, G and $\mathrm{H}$. 

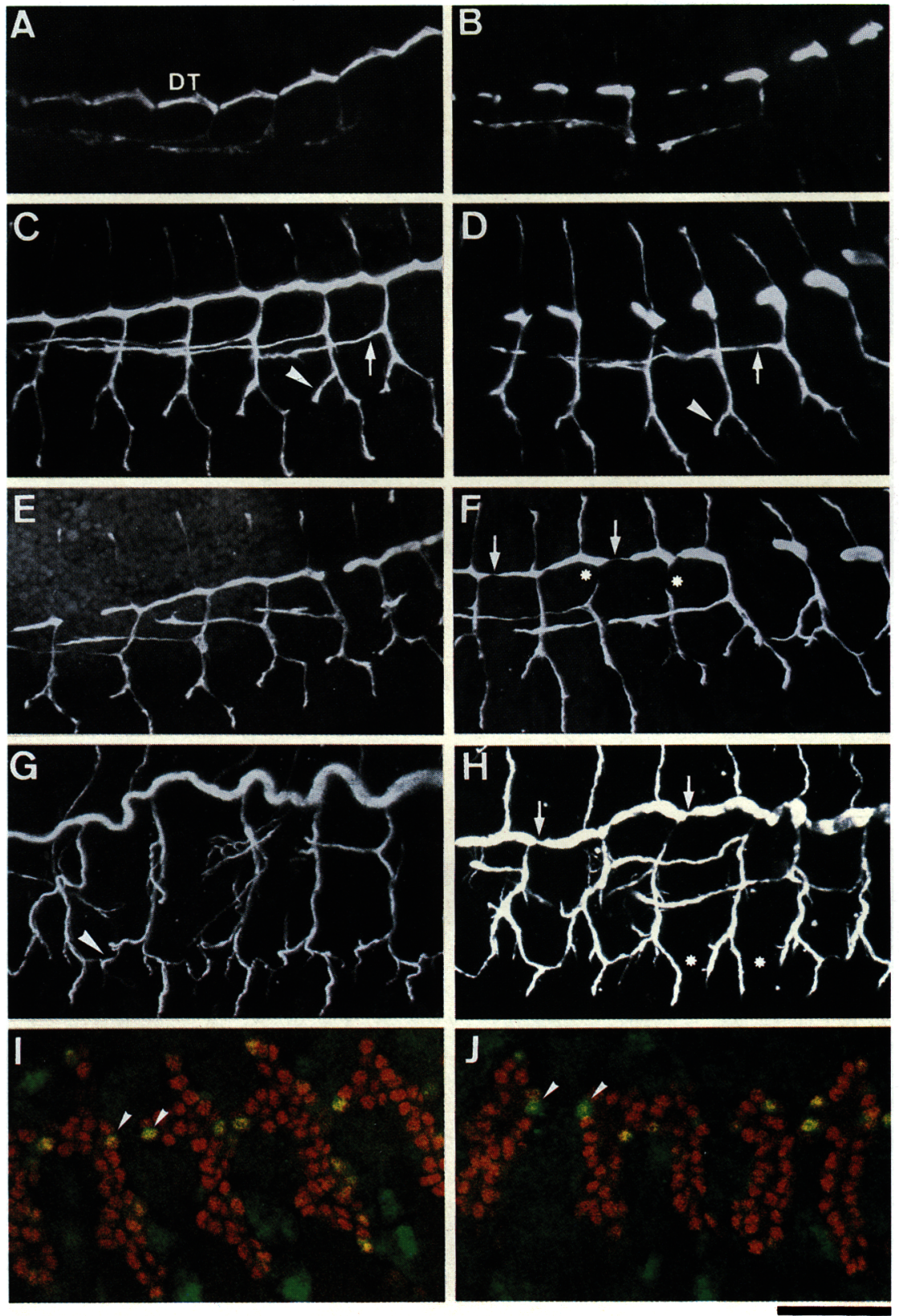

Figure 6. Outgrowth and fusion of tracheal branches were blocked in shg mutants. All photographs are lateral views, and oriented with anterior to the left and ventral down. $(A-H)$ Images of tracheal lumina, stained with no. 84 , which were constructed by overlaying multiple optical sections. $(A, B)$ Mid-stage 13 embryos of the wild type and $E 2 / D 17$, respectively. In the wild type, DTs were about to fuse together. $(C, D)$ Stage 14 embryos of the wild type and the deficiency, respectively. The DT fusion has already taken place at late stage 13 in the wild type. Arrows represent visceral branches, and arrowheads point to LTs. (E) Stage 14 deficiency embryo that was partially rescued by the expression of the $h s p-$ cadE transgene. $(F)$ Stage $14 s h g^{2}$ mutant. Arrows indicate examples of constrictions at the fusion points of DTs. Interruptions of tracts are labeled by asterisks $\left({ }^{*}\right) .(G, H)$ Stage 16 wild-type and $s h g^{E 17 B}$ embryos, respectively. This $\operatorname{shg}^{E 17 B}$ mutant $(H)$ is slightly younger than the normal embryo of $G$. In the mutant, every DT joint was pinched (arrows) and some LTs were not connected (asterisks). (I,I) Early stage 13 embryos of the wild type and the deficiency, respectively, that were doublestained for $\beta$-gal expression of a breathlessenhancer trap line (red) and esg (yellow or green). Tracheal tip cells expressed esg (arrowheads in $I$ and $I /$. Scale bar, $50 \mu \mathrm{m}$.

\section{Discussion}

We presented evidence that the processes of dynamic epithelial reorganization require the zygotic expression of DE-cadherin, encoded by shotgun (shg). Elimination of the zygotic expression destroyed the MT and the ventral epidermis, and blocked distinct aspects of tracheal tree formation. A strong shg mutation was reported previously to affect the cell morphology of midgut epithelia, which are of endodermal origin (Tepass and Hartenstein 1994b). Assembled midgut epithelial cells remained round or cuboidal instead of becoming columnar. This phenotype is consistent with our finding of the role of $D E$-cadherin in epithelial reorganization processes.

\section{The role of maternal DE-cadherin expression}

Unexpectedly, most of the epithelial tissues were not severely disorganized by shg mutations. They maintained not only their mutual associations but also apicobasal polarity. Even after fragmentation of the MT, the mutant cells still preserved these two aspects of cellular characters. The zygotic null mutant contained a significant amount of maternally derived $D E$-cadherin, suggesting that this maternal pool may contribute to the maintenance of the general epithelial architecture. To test this posibility, we attempted to generate germ-line clones, but the obtained clones displayed blocked oogenesis (H. Oda, unpubl.). For this reason, we were unable to 
Figure 7. Tracheal development in arm and wg mutants. Lateral views oriented with anterior to the left and ventral down. Staining and image reconstruction were done as explained in Fig. 6. $\{A, B \mid$ arm null mutants $\left(a \mathrm{rm}^{Y D 35}\right)$ of late stage 13 and early stage 16 , respectively. Dorsal longitudinal trunks were totally missing (cf. $A$ with Fig. $6 \mathrm{C}$ and $B$ with Fig. 6G). Lateral trunks (arrowhead) did not fuse with each other in B. Arrows represent visceral branches. (C) Stage 16 arm hypomorph $\left(\mathrm{arm}^{H 8.6}\right)$. Connections of dorsal and lateral trunks were incomplete (arrow and asterisk, respectively). (D) Stage 14 wg null mutant $\left(w g^{C X 4}\right)$. Many of the tracheal cells remained on the surface ectoderm (star), but a dorsal trunk was generated (arrow). In $\operatorname{arm}^{Y D 35}$, no immunoreactivity of no. 84 could be detected on the embryonic surface. Scale bar, $50 \mu \mathrm{m}$.
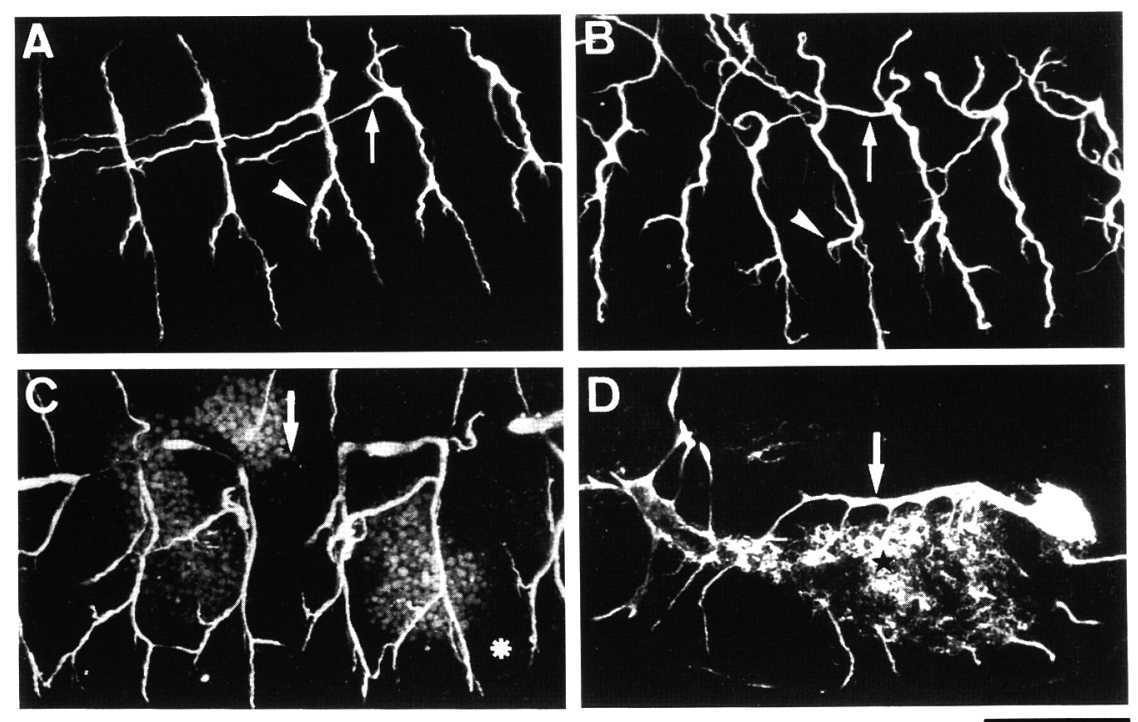

study the effect of the removal of maternal $D E$-cadherin on embryogenesis. The same type of experiment was done successfully by another group who employed weak alleles (Tepass et al., this issue). Those embryos produced only small patches of the cuticle over their whole body. This cuticle pattern strongly suggests that all of the cuticle-secreting epithelia, including the entire epidermis, were totally destroyed. This observation supports the idea that the maternal $D E$-cadherin plays an essential role in the initial formation and maintenance of epithelial tissues.

The above argument about the maternal contribution of $D \mathrm{E}$-cadherin, however, appears inconsistent with our immunohistological observations of the zygotic shg mutants; that is, neither $D E$-cadherin nor its associated proteins, D $\alpha$-catenin and Arm, were highly concentrated at cell-cell boundaries in embryos at late stages, for example, after stage 13. Nevertheless, the results of the shg germ-line clones, together with those of the zygotic mutants, indicate that the drastically reduced levels of the $D E$-cadherin/catenin complex can still manage to maintain the epithelial architecture once it has been established. Perhaps, our immunohistological method was not sensitive enough for fully detecting the maternal molecules.

Previously we showed similar features in the expression patterns and in vitro activities of $D E$-cadherin and vertebrate E-cadherin, and considered $D \mathrm{E}$-cadherin to be a Drosophila homolog of the vertebrate E-cadherin (Oda et al. 1994). The shg studies reinforce the notion that these two proteins appear to be equivalent in the sense of in vivo functions as well.

\section{The role of $\mathrm{DE}$-cadherin in dynamic epithelial rearrangements}

How does the zygotic $D E$-cadherin control epithelial reorganization? During cell rearrangement within a tissue like the MT, cells must cycle a rapid breakdown and a re-establishment of their mutual adhesion without creating intercellular breakages (Gumbiner 1992). Another type of dynamic cell adhesion is found in the ventral neurogenic region of the ectoderm, where epidermal precursors have to remake new contacts as soon as neuroblasts delaminate (Hartenstein and Campos-Ortega 1984). In the shg zygotic mutants, epithelial structures were broken down in both the MT and the neuroectoderm (this study; Tepass et al., this issue). These severe damages present a sharp contrast to the undisrupted tissues including the dorsal epidermis and the hindgut. The dorsal epidermis is morphogenetically less active than the ventral epidermis at the stage of neuroblast segregation, and so is the hindgut than the MT during the elongation of the latter. Maternal $D E$-cadherin molecules, detected in the ventral epidermis and also presumably present in the MTs, could not support the reorganization of these tissues. We therefore speculate that the zygotic $D E$-cadherin expression is critically required for the establishment of new cell-cell associations and that the maternal molecules cannot perform this task. It is conceivable that the pool of the maternal $D E$-cadherin is not sufficient in amount, and/or it cannot be recycled, to establish new cell-cell adhesions. That is, the maternal molecules may serve only for the maintenance of the already established cell-cell junctions, whereas the ones supplied by the zygotic expression are utilized for active cell repositioning.

In the absence of well-controlled intercellular adhesion systems, the activated cell motility would cause a disruption of epithelial monolayers. Adhesion molecules need to be delivered rapidly to appropriate positions to form new cell-cell contacts in a manner coordinated with the cell movement. Interaction of $D E$-cadherin with the actin-based cytoskeleton via catenins likely supports an efficient redistribution of the molecules on the plasma membrane. Also, detachment of cells must 


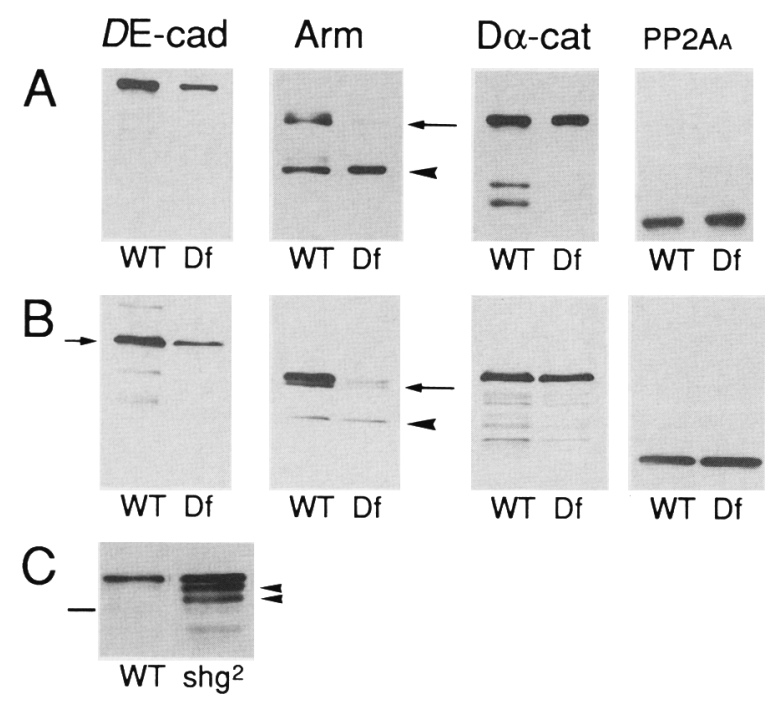

Figure 8. Western blotting analyses of deficiency and $s h g^{2} \mathrm{mu}-$ tant embryos. $(A, B) D E$-cadherin (DE-cad), $\beta$-catenin/Arm, $D \alpha$ catenin $(D \alpha$-cat $)$ in deficiency embryos (Df) were compared with those in wild-type Oregon R (WT). E2/D17 embryos (22-26 hr) $(A)$ or 13-16 hr $D f(2 R) D 17$ homozygotes $(B)$ were used. In $B$, besides the mature form of $D E$-cadherin $(150 \mathrm{kD}$, short arrow), a larger precursor is seen. Two Arm isoforms are generated, an epithelial type (long arrow, 105-110 kD) and a smaller neural type (arrowhead, $82 \mathrm{kD}$ ) (J. Loureiro and M. Peifer, pers. comm.). $D \alpha$-cat is $110 \mathrm{kD}$ in its full size, and smaller bands seen are most likely degradation products. The $65-\mathrm{kD}$ subunit (A subunit) of protein phosphatase 2A (PP2A $\mathrm{A}_{\mathrm{A}}$; Shiomi et al. 1994) was used as a standard to compare the amounts of proteins loaded. In each lane, a whole lysate equivalent to $\sim 15$ embryos was loaded. Proteins in the deficiency embryos were more extractable, probably because of the elimination of most ventral cuticle. (C) Patterns of DE-cadherin in Oregon R (WT) and $s h g^{2}$ homozygote $\left(\operatorname{shg}^{2}\right)$. Degraded $D E$-cadherin molecules were detected in the shg ${ }^{2}$ extract (arrowheads). A position of $\beta$-galactosidase ( $116 \mathrm{kD}$ ) is indicated by a bar in $C$.

be controlled during cell rearrangement processes. A study done by use of E-cadherin $/ \alpha$-catenin fusion proteins suggests that catenins play a pivotal role in reversibility of intercellular adhesion (Nagafuchi et al. 1994). Therefore, cadherins seem to be ideal regulators of dynamic cell-cell adhesion. Recently one of the Xenopus cadherins was implicated in gastrulation movements (Lee and Gumbiner 1995); this finding appears to be consistent with ours on the shg zygotic mutants.

In normal MT organogenesis, cellular rearrangement follows the termination of cell proliferation. Although we could not determine exactly when the proliferation phase was over in the mutant organ, the disintegration process was observed at stages when cells were supposed to be still dividing in the wild type. In the normal embryo, MT cells start proliferation after almost all of the other ectodermal epithelia have finished cell division (for review, see Skaer 1993). During mitosis, intercellular junctions persist (Tepass and Hartenstein 1994a), and $D E$-cadherin and catenins stay at the apical positions of epithelial cell contacts (Woods and Bryant 1993; Harten- stein et al. 1994; T. Uemura, unpubl.). The mutant epithelial sheet may not be able to stand sufficiently the mechanical stress brought about by rapid proliferation, resulting in a certain extent of epithelial disorganization. This initial rupture of cell contacts may be exaggerated once the cells acquire motility and undergo rearrangement.

\section{DE-cadherin and Arm functions in the extension and fusion of tracheal branches}

Tracheal tubular extension was partially blocked in the shg null mutant. A number of other gene products also play important roles in embryonic tracheal patterning; they include Breathless, a fibroblast growth factor (FGF) receptor homolog (Klämbt et al. 1992), Thick veins, a receptor serine/threonine kinase (Affolter et al. 1994), and Drifter, a POU-domain transcription factor (Anderson et al. 1995). Compared with the phenotypes of mutants of these genes, the shg phenotypes are unique in that the defects were rather restricted to a subset of branches that perform fusion, that is, fusion branches (Manning and Krasnow 1993). Although cellular mechanisms for elaboration of individual branch extensions are not fully understood, such restricted effects of the shg mutations suggest that different mechanisms for tubular outgrowth are operative between the fusion branches and the other branches. For the elongation of the fusion branches, it is likely that cell rearrangement may be a major force, as is the case in MT development. In contrast, for the other branches, for example, visceral branches, mechanisms such as simple cell shape changes, which would not accompany cellular repositioning, might be essential. The tracheal epithelial structure was damaged much less seriously than that of the MTs. This could be attributable to possible involvement of multiple mechanisms, as described above, operating in the elongation processes.

Analysis of partial loss-of-function shg mutants revealed another $D E$-cadherin-dependent process in the tracheal fusion. In the weak allele $\operatorname{shg}^{E 17 B}$, DTs were able to extend far enough so that their tracheal tip cells established physical contact with each other, and thus lumina were generated to connect flanking branches. However, widening of the tract diameter was blocked at every fusion point. To understand more definitively the roles of $D E$-cadherin in the fusion processes, we must clarify the cellular basis of the fusion, in particular, the behavior of the tip cells.

Besides the shg mutants, arm mutants also showed malformation of the fusion branches. This is not surprising superficially, because Arm and DE-cadherin are supposed to interact physically with each other in their function. However, the situation in the arm mutant is somewhat complicated. In the arm zygotic null mutant, $D E$-cadherin proteins were detectable at the apical side of cell boundaries in all epithelia, although the signal was weaker than that in wild-type siblings /data not shown). Those cadherin molecules probably form complexes with maternally derived Arm (Riggleman et al. 

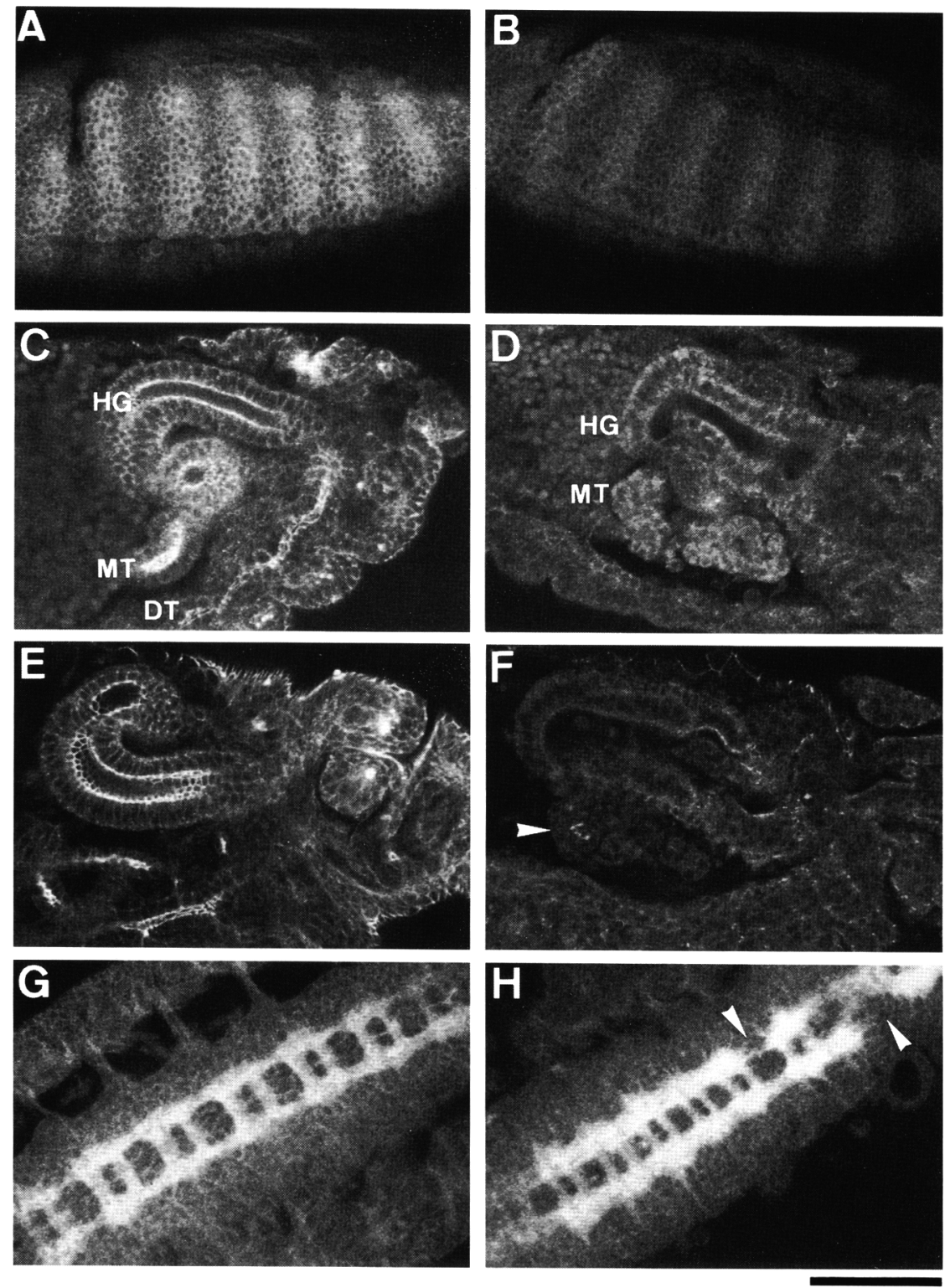

Figure 9. Distribution of catenin signals in the deficiency embryos (right column) and wild-type siblings (left column). $(A-D)$ Arm staining of formaldehyde-fixed embryos. $(E-H) D \alpha$-catenin staining of embryos fixed by the heat-methanol method $(E, F)$ or by formaldehyde $(G, H) .(A, B)$ Stage 10 Arm stripes in ventrolateral views. (CF) Dorsolateral views of stage $13 / 14 \mathrm{em}-$ bryos. (MT) Malpighian tubules; (HG) hindgut; (DT) dorsal longitudinal trunks of the trachea tree. The arrowhead in $F$ indicates a residual $D \alpha$-catenin signal in the mutant MT that did not fall apart completely in this stage of the embryo. $(G, H)$ Ventral views of the central nervous system in stage 14 wild-type and stage 15 deficiency embryos, respectively. Axon tracks in the deficiency embryo were stained as strongly as in the wild type, although the deficiency embryo had a couple of breaks in the longitudinal connectives and commissures (arrowheads). The deficiency embryos were a $D f(2 R) E 2$ homozygote $(B)$ and a transheterozygote of E2/D17 $(D, F, H)$. Confocal images were processed with identical parameters for $A$ and $B, C$ and $D, E$ and $F$, and $G$ and $H$. Anterior is to the left. Scale bar, $75 \mu \mathrm{m}$ in $A$ and $B$, and 50 $\mu \mathrm{m}$ in $\mathrm{C}-\mathrm{H}$.
1990), suggesting that they are functioning as adhesion machinery to a certain extent. Consistently, the arm null mutant exhibited normal extension of MTs as opposed to the shg mutant. Therefore, the tracheal malformation in the arm embryo cannot simply be explained by a reduction in the activity of the cadherin-catenin adhesion system. Arm is considered to work as a signal transducer downstream of $\mathrm{Wg}$ in patterning of the embryonic epidermis (for review, see Peifer 1995). However, tracheal phenotypes in arm and $w g$ mutants indicate that these two genes function, at least in part, separately in this tubulogenic morphogenesis.

Finally, it would be intriguing to ask whether DE-cadherin is involved in the $\mathrm{Wg}$ signaling cascade for segment polarity determination. The denticle patterns in the shg null mutant did not provide positive evidence for this possible linkage, although the loss of most ventral cuticles hindered careful analyses of the patterning. Weak- ening of the overall Arm stripe pattern was observed in the shg null mutant. However, this reduction of the Arm level became apparent during stage 10, when most cells no longer require active $\mathrm{Wg}$ for stable engrailed (en) expression (Bejsovec and Martinez Arias 1991; Heemskerk et al. 1991). The maternally derived $D E$-cadherin perhaps sustained the Arm level at the critical period for $\mathrm{Wg}$ signaling, and thus the effect of loss of $D E$-cadherin on segment polarity could not be examined. Further studies are necessary to disclose whether $D E$-cadherin is actively involved in the $\mathrm{Wg}$ pathway.

\section{Materials and methods}

Drosophila strains

Isolation of deficiency chromosomes in the 57B region is described elsewhere (Kraut and Campos-Ortega 1996). Embryos from each line were stained with an antibody to $D E$-cadherin, 
and we found that signals were undetectable in late homozygous $D f(2 R) E 2$ embryos. $D f(2 R) E 2 /+$ and $D f(2 R) D 17 /+$ polytene chromosomes were then hybridized with $D E$-cadherin cDNA probes, and we confirmed that both deficiencies completely lacked shg. $D f(2 R) D 17, D f(2 R) p 113, s h g^{2}$, and $w_{g} C X 4$ were provided from the Bloomington Stock Center. $D f(2 R) F 36$ and $D f(2 R) P L 3$ were reported previously (O'Donnell et al. 1989).

Before isolation of $D f(2 R) E 2$ and finding that shg encodes $D E-$ cadherin, we tried to find candidates of cadE mutants among a collection of lethal strains that mapped within $D f(2 R) D 17$. For this purpose, we used a subset of the lethal lines that positioned within $D f(2 R) D 17$ but outside all internal deficiencies like $D f(2 R) F 36$ and $D f(2 R) P L 3$. These lethal strains were provided from Dr. Janis O'Donnell (University of Alabama, Tuscaloosa). Embryos of those individual lines were stained with the anti$D E$-cadherin antibody; two lines, 1(2)E17B and 1(2)SHN-1, showed ectopic signals in axon tracks in the CNS. However, cadE mRNA was detected only in midline glial cells in these lines as in the wild type (T. Usui and T. Uemura, unpubl.). We did not study further the molecular basis of the ectopic protein distribution in these lines. By complementation tests with $s h g^{2}$, we found that those two were allelic to shg, so they were renamed $s h g^{E 17 B}$ and $s h g^{S H N-1}$, respectively.

In FlyBase, we found that the Berkeley Drosophila Genome Project identified three strains with PZ-element insertions into 57B13-14: 1(2)03050, 1(2)07206, and 1(2)10469 (FlyBase 1994; Spradling et al. 1995; Berkeley Drosophila Genome Project, pers. comm.). These three lines were provided from the Bloomington Stock Center. 1(2)10469 did not complement the three shg alleles that we described above, and we renamed this line $s h g^{P 10469}$. The PZ-element was mobilized by $\Delta 2-3$ (Robertson et al. 1988). Adult escapers homozygous for $s g^{P 10469}$ showed a patterning defect along the anterior wing margin (Y. Kataoka and T. Uemura, unpubl.).

$\mathrm{arm}^{\text {YD35 }}$ and $\mathrm{arm}^{H 8.6}$ were provided by Dr. Mark Peifer (University of North Carolina, Chapel Hill). arm $^{H 8.6}$ is a temperature-sensitive allele (Klingensmith et al. 1989), and embryos homozygous for it were incubated at $25^{\circ} \mathrm{C}$ for tracheal analyses. The following enhancer trap lines were used: A154.2M3 (Bellen et al. 1989) to study MTs and 6-81a (Klämbt et al. 1992) for tracheal cells.

\section{Isolation of genomic DNA clones of the DE-cadherin gene}

We isolated phage clones from an Oregon- $\mathrm{R}$ genomic library $(\mathrm{L}$. Jan and Y.N. Jan, University of California, San Franciscol using $D E$-cadherin cDNA clones (Oda et al. 1994). About $20 \mathrm{~kb}$ of genomic DNA in total was isolated, and we roughly determined positions of exons by hybridizing various cDNA fragments to the genomic clones, comparison of restrictions sites, and partial genomic sequencing. The position of the $\operatorname{shg}^{P 10469}$ insertion was determined by sequencing the plasmid rescue fragment.

\section{Antibodies and Western blotting}

Rat antibodies to DE-cadherin (DCAD1 and DCAD2), D $\alpha$-catenin (DCAT1), Esg, and protein phosphatase $2 \mathrm{~A}_{\mathrm{A}}$ were generated previously (Oda et al. 1993, 1994; Fuse et al. 1994; Shiomi et al. 1994). DCAD1 was used for Western analyses and DCAD2 for immunostaining embryos. Other antibodies used were as follows: 7Al (mouse anti-Arm; Peifer 1993), Cq4 (mouse antiCRB; Tepass and Knust 1993), no. 84 (guinea pig tracheal-specific antibody; Klämbt et al. 1992), DA1B6 (mouse anti-fasciclin III; Gauger et al. 1987), no. 243 (rabbit anti- $\beta_{\text {Heavy }}$-spectrin antibody; Thomas and Kiehart 1994), and rabbit anti- $\beta$-galactosidase (Cappel). To prepare samples for Western blots, we homog- enized dechorionated embryos in a $1 \times$ Laemmli sample buffer containing $1 \mathrm{~mm}$ phenylmethylsulfonyl fluoride, sonicated the homogenate, and immediately boiled it for 3-4 min. To detect signals in Western blots, we employed an ECL kit (Amersham).

\section{Observation of embryos}

For immunostaining, embryos were usually fixed in $3.5 \%$ formaldehyde in $0.1 \mathrm{M}$ phosphate buffer $(\mathrm{pH} 7.4)$, or a protocol of heat methanol fixation was followed (U. Tepass, pers. comm.). The heat methanol fix was employed for $\beta_{\text {Heavy }}$-spectrin (Fig. 4H,I) and $D \alpha$-catenin (Fig. 9E,F) stainings. $D \alpha$-catenin is concentrated at the ZA in heat-fixed embryos (U. Tepass, pers. comm.). We did not employ any fix solutions containing EDTA or EGTA, because cadherins are degraded easily under $\mathrm{Ca}^{2+}$-free conditions. Signals were detected by use of an ABC Elite kit (Vectastain) or by fluorescence labeling (Oda et al. 1994). A combination of FITC and Texas Red was employed for double labeling, and embryos were viewed with a Zeiss laser scanning confocal microscope. MTs in live embryos were observed with Normarski optics except that a condenser for dark-field microscopy was used.

\section{Heat shock experiments}

A 5-kb fragment of the DE-cadherin cDNA was isolated from pRmHa3-DECH (Oda et al. 1994) and inserted in to pCaSpeR-hs (Thummel et al. 1988). The resultant plasmid, phs-DECH, was microinjected into $W^{1118} ; \Delta 2-3$ TM3 Sb/Dr (Robertson et al. $1988)$ to produce transgenic flies. Two established lines were used for rescue experiments: DECH 1-1-2, which has phs$\mathrm{DECH}$ inserted into the $\mathrm{X}$ chromosome, and DECH 2-3 (with insertion into the third chromosome). For the rescue experiments we collected males and virgin females, each of which was heterozygous for $D f$ or for $s h g^{2}$ and carried one copy of the DECH chromosome. Those males and females were crossed to each other. Embryos were collected, aged for $3.5-5 \mathrm{hr}$ at $25^{\circ} \mathrm{C}$, and heat-shocked for $30 \mathrm{~min}$ in a $37^{\circ} \mathrm{C}$ water bath. They were then aged to stage $13-14$, to stage 16 for observation of tracheal development, or to the end of embryogenesis for examination of cuticles and MTs. Embryos of the deficiency or $s h g^{2}$ strains without phs-DECH were heat-shocked in parallel for the control. As for DECH 1-1-2 and DECH 2-3, the overexpression was confirmed by RNA in situ hybridization, Western blot analysis, and immunostaining. Both chromosomes exhibited similar levels of the $D E$-cadherin induction and equally rescued the embryos from the mutant phenotypes.

\section{Acknowledgments}

We would like to thank the Bloomington Stock Center and M. Peifer for strains; and E. Knust, M. Leptin, M. Peifer, B. Shilo, and $\mathrm{G}$. Thomas for antibodies. We are grateful to F. Matsuzaki for pCaSpeR-hs; K. Ito for comments about CNS phenotypes; R. Ueda for technical advice for observation of live embryos; and $\mathrm{T}$. Ito and M. Murata for allowing us to use their confocal microscope. Finally, we thank very much J. Campos-Ortega (Institut für Entwicklungsbiologie of Universität zu Köln), J. O'Donnell, and R. Boswell for collections of unpublished lines, A. Nose and T. Umeda for various materials and technical advice, and V. Hartenstein, U. Tepass, and other people in the Hartenstein laboratory for sharing their results prior to publication. This work was supported by a grant-in-aid for Creative Fundamental Research from the Ministry of Education, Science, and Culture of Japan, and by a grant from the Human Frontier Science Program. H.O. is a recipient of a Fellowship of the Japan Society for the Promotion of Science for Junior Scientists. 
The publication costs of this article were defrayed in part by payment of page charges. This article must therefore be hereby marked "advertisement" in accordance with 18 USC section 1734 solely to indicate this fact.

\section{References}

Affolter, M., D. Nellen, U. Nussbaumer, and K. Basler. 1994. Multiple requirements for the receptor serine/threonine kinase thick veins reveal novel functions of TGF $\beta$ homologe during Drosophila embryogenesis. Development 120: 31053117.

Anderson, M.G., G.L. Perkins, P. Chittick, R.J. Shrigley, and W.A. Johnson. 1995. drifter, a Drosophila POU-domain transcription factor, is required for correct differentiation and migration of tracheal cells and midline glia. Genes \& Dev. 9: $123-137$.

Bejsovec, A. and A. Martinez Arias. 1991. Roles of wingless in patterning the larval epidermis of Drosophila. Development 113: 471-485.

Bellen, H.J., C.J. O'Kane, C. Wilson, U. Grossniklaus, R.K. Pearson, and W.J. Gehring. 1989. P-element-mediated enhancer detection: A versatile method to study development in Drosophila. Genes \& Dev. 3: 1288-1300.

Clark, H.F., D. Brentrup, K. Schneitz, A. Bieber, C. Goodman, and M. Noll. 1995. Dachsous encodes a member of the cadherin superfamily that controls imaginal disc morphogenesis in Drosophila. Genes \& Dev. 9: 1530-1542.

Eaton, S. and K. Simons. 1995. Apical, basal, and lateral cues for epithelial polarization. Cell 82: 5-8.

FlyBase. 1994. FlyBase-The Drosophila database. Nucleic Acids Res. 22: 3456-3458.

Fuse, N., S. Hirose, and S. Hayashi. 1994. Diploidy of Drosophila imaginal cells is maintained by a transcriptional repressor encoded by escargot. Genes \& Dev. 8: 2270-2281.

Gauger, A., M.A. Clicksman, R. Salatino, J.M. Condie, G. Schubiger, and D.L. Brower. 1987. Segmentally repeated pattern of expression of a cell surface glycoprotein in Drosophila embryos. Development 100: 237-244.

Gumbiner, B.M. 1992. Epithelial morphogenesis. Cell 69: 385387.

Hartenstein, V. and J.A. Campos-Ortega. 1984. Early neurogenesis in wild type Drosophila melanogaster. Wilhelm Roux's Arch. Dev. Biol. 193: 308-325.

Hartenstein, V., A. Younossi-Hartenstein, and A. Lekven. 1994. Delamination and division in the Drosophila neurectoderm: Spatiotemporal pattern, cytoskeletal dynamics, and common control by neurogenic and segment polarity genes. Dev. Biol. 165: 480-499.

Heasman, J., D. Gingsberg, B. Geiger, K. Goldstone, T. Pratt, C. Yoshida-Noro, and C. Wylie. 1994. A functional test for maternally inherited cadherin in Xenopus shows its importance in cell adhesion at the blastula stage. Development 120: 4957.

Heemskerk, J., S. DiNardo, R. Kostriken, and P.H. O'Farrell. 1991. Multiple modes of engrailed regulation in the progression towards cell fate determination. Nature 352: 404-410.

Hermiston, M.L. and J.I. Gordon. 1995. In vivo analysis of cadherin function in the mouse intestinal epithelium: Essential roles in adhesion, maintenance of differentiation, and regulation of programmed cell death. J. Cell Biol. 129: 489-506.

Hinck, L., I.S. Nathke, J. Papkoff, and W.J. Nelson. 1994. $\beta$-catenin: A common target for the regulation of cell adhesion by Wnt-1 and Src signaling pathways. Trends Biochem. Sci. 19: $538-542$.
Hirano, S., N. Kimoto, Y. Shimoyama, S. Hirohashi, and M. Takeichi. 1992. Identification of a neural $\alpha$-catenin as a key regulator of cadherin function and multicellular organization. Cell 70: 293-301.

Kawanishi, J., J. Kato, K. Sasaki, S. Fujii, N. Watanabe, and Y. Niitsu. 1994. Loss of E-cadherin-dependent cell-cell adhesion due to mutation of the $\beta$-catenin gene in a human cancer cell line, HSC-39. Mol. Cell. Biol. 15: 1175-1181.

Keller, R., J. Shih, and C. Domingo. 1992. The patterning and functioning of protrusive activity during convergence and extension of the Xenopus organiser. Development (Suppl.) 81-91.

Kintner, C. 1992. Regulation of embryonic cell adhesion by the cadherin cytoplasmic domain. Cell 69: 225-236.

Klämbt, C., L. Glazer, and B.-Z. Shilo. 1992 breathless, a Drosophila FGF receptor homolog, is essential for migration of tracheal and specific midline glial cells. Genes \& Dev. 6: $1668-1678$.

Klingensmith, J., E. Noll, and N. Perrimon. 1989. The segment polarity phenotype of Drosophila involves differential tendencies toward transformation and cell death. Dev. Biol. 134: 130-145.

Kraut, R. and J.A. Campos-Ortega. 1996. inscuteable, a neural precursor gene of Drosophila, encodes a candidate for a cytoskeleton adaptor protein. Dev. Biol. (in press.)

Larue, L., M. Ohsugi, J. Hirchenhain, and R. Kemler. 1994. E-cadherin null mutant embryos fail to form a trophectoderm epithelium. Proc. Natl. Acad. Sci. 91: 8263-8267.

Lee, C.-H. and B.M. Gumbiner. 1995. Disruption of gastrulation movements in Xenopus by a dominant-negative mutant for C-cadherin. Dev. Biol. 171: 363-373.

Levine, E., C.H. Lee, C. Kintner, and B.M. Gumbiner. 1994. Selective disruption of E-cadherin function in early Xenopus embryos by a dominant negative mutant. Development 120: 901-909.

Mahoney, P.A., U. Weber, P. Onofrechuk, H. Biessmann, P.J. Bryant, and C.S. Goodman. 1991. The fat tumor suppressor gene in Drosophila encodes a novel member of the cadherin gene superfamily. Cell 67: 853-868.

Manning, G. and M.A. Krasnow. 1993. Development of the Drosophila tracheal system. In The development of Drosophila melanogaster (ed. M. Bate and A. Martinez Arias), pp. 609-685. Cold Spring Harbor Laboratory Press, Cold Spring Harbor, NY.

McCrea, P.D., C.W. Turck, and B. Gumbiner. 1991. A homolog of the armadillo protein in Drosophila (Plakoglobin) associated with E-cadherin. Science 254: 1359-1361.

McNeill, H., M. Ozawa, R. Kemler, and W.J. Nelson. 1990. Novel function of the cell adhesion molecule uvomorulin as an inducer of cell surface polarity. Cell 62: 309-316.

Miller, K.G., C.M. Field, and B.M. Alberts. 1989. Actin-binding proteins from Drosophila embryos: A complex network of interacting proteins detected by F-actin affinity chromatography. J. Cell Biol. 109: 2963-2975.

Mlodzik, M. and Y. Hiromi. 1992. Enhancer trap method in Drosophila: Its application to neurobiology. In Gene expression in neural tissues (Methods in Neurosciences 9) (ed. P.M. Conn), pp. 397-414. Academic Press, San Diego, CA.

Nagafuchi, A., S. Ishihara, and S. Tsukita. 1994. The roles of catenins in the cadherin-mediated cell adhesion: Functional analysis of E-cadherin- $\alpha$ catenin fusion molecules. J. Cell Biol. 127: 235-245.

Noordermeer, J., J. Klingensmith, N. Perrimon, and R. Nusse. 1994. dishevelled and armadillo act in the wingless signaling pathway in Drosophila. Nature 367: 80-83. 
Nüsslein-Volhard, C., E. Wieschaus, and H. Kluding. 1984. Mutations affecting the pattern of the larval cuticle in Drosophila melanogaster. Wilhelm Roux's Arch. Dev. Biol. 193: $267-282$

O'Donnell, J., R. Boswell, T. Reynolds, and W. Mackay. 1989. A cytogenetic analysis of the Punch-tudor region of chromosome 2R in Drosophila melanogaster. Genetics 121: 273280.

Oda, H., T. Uemura, K. Shiomi, A. Nagafuchi, S. Tsukita, and M. Takeichi. 1993. Identification of a Drosophila homologue of $\alpha$-catenin and its association with the armadillo protein. J. Cell Biol. 121: 1133-1140.

Oda, H., T. Uemura, Y. Harada, Y. Iwai, and M. Takeichi. 1994. A Drosophila homolog of cadherin associated with Armadillo and essential for embryonic cell-cell adhesion. Dev. Biol. 165: 716-726.

Oyama, T., Y. Kanai, A. Ochiai, S. Akimoto, T. Oda, T. Yanagihara, A. Nagafuchi, S. Tsukita, S. Shibamoto, F. Ito, M. Takeichi, H. Matsuda, and S. Hirohashi. 1995. A truncated $\beta$-catenin disrupts the interaction between E-cadherin and $\alpha$-catenin: A cause of loss of intercellular adhesiveness in human cancer cell lines. Cancer Res. 54: 6282-6287.

Patel, N.H., P.M. Snow, and C.S. Goodman. 1987. Characterization and cloning of fasciclin III: A glycoprotein expressed on a subset of neurons and axon pathways in Drosophila. Cell 48: 975-988.

Peifer, M. 1993. The product of the Drosophila segment polarity gene armadillo is part of a multi-protein complex resembling the vertebrate adherens junction. J. Cell Sci. 105: 9931000 .

- 1995. Cell adhesion and signal transduction: The Armadillo connection. Trends Cell Biol. 5: 224-229.

Peifer, M. and E. Wieschaus. 1990. The segment polarity gene armadillo encodes a functionally modular protein that is the Drosophila homolog of human plakoglobin. Cell 63: 11671178.

Peifer, M., D. Sweeton, M. Casey, and E. Wieschaus. 1994. wingless signal and Zeste-white 3 kinase trigger opposing changes in the intracellular distribution of Armadillo. Development 120: 369-380.

Riethmacher, D., V. Brinkmann, and C. Birchmeier. 1995. A targeted mutation in the mouse E-cadherin gene results in defective preimplantation development. Proc. Natl. Acad. Sci. 92: 855-859.

Riggleman, B., P. Schedl, and E. Wieschaus. 1990. Spatial expression of the Drosophila segment polarity gene armadillo is posttranscriptionally regulated by wingless. Cell 63: 549560 .

Robertson, H.M., C.R. Preston, R.W. Phillis, D. JohnsonSchlitz, W.K. Benz, and W.R. Engels. 1988. A stable source of P-element transposase in Drosophila melanogaster. Genetics 118: 461-470.

Shiomi, K., M. Takeichi, Y. Nishida, Y. Nishi, and T. Uemura. 1994. Alternative cell fate choice induced by low-level expression of a regulator of protein phosphatase $2 \mathrm{~A}$ in the Drosophila peripheral nervous system. Development 120: 1591-1599.

Siegfried, E., E. Wilder, and N. Perrimon. 1994. Components of wingless signaling in Drosophila. Nature 367: 76-80.

Skaer, H. 1989. Cell division in Malpighian tubule development in D. melanogaster is regulated by a single tip cell. Nature 342: 566-569.

. (1992). Development of the insect malpighian tubule. In Epithelial organization and development (ed. T.P. Fleming), pp. 191-218. Chapman \& Hall, London, UK.
1993. The alimentary canal. In The development of Drosophila melanogaster (ed. M. Bate and A.M. Arias), pp. 941-1012. Cold Spring Harbor Laboratory Press, Cold Spring Harbor, NY.

Spradling, A.C., D.M. Stern, I. Kiss, J. Roote, T. Laverty, and G.M. Rubin. 1995. Gene disruptions using $P$ transposable elements: An integral component of the Drosophila genome project. Proc. Natl. Acad. Sci. 92: 10824-10830.

Takeichi, M. 1995. Morphogenetic roles of classic cadherins. Curr. Opin. Cell Biol. 7: 619-627.

Tepass, U. and V. Hartenstein. 1994a. Epithelium formation in the Drosophila midgut depends on the interaction of endoderm and mesoderm. Development 120: 579-590.

- 1994b. The development of cellular junctions in the Drosophila embryo. Dev. Biol. 161: 563-596.

Tepass, U. and E. Knust. 1993. crumbs and stardust act in a genetic pathway that controls the organization of epithelia in Drosophila melanogaster. Dev. Biol. 159: 311-326.

Tepass, U., E. Gruszynski-DeFeo, T.A. Haag, L. Omatyar, T. Török, and V. Hartenstein. 1996. shotgun encodes Drosophila E-cadherin and is preferentially required during cell rearrangement in the neuroectoderm and other morphogenetically active epithelila. Genes \& Dev. (this issue).

Thomas, G.H. and D.P. Kiehart. 1994. $\beta_{\text {Heavy }}$-spectrin has a restricted tissue and subcellular distribution during Drosophila embryogenesis. Development 120: 2039-2050.

Thummel, C.S., A.M. Boulet, and H.D. Lipshitz. 1988. Vectors for Drosophila P-element-mediated transformation and tissue culture transfection. Gene 74: 445-456.

Tsukita, S., S. Tsukita, A. Nagafuchi, and S. Yonemura. 1992. Molecular linkage between cadherins and actin filaments in cell-cell adherens junctions. Curr. Opin. Cell Biol. 4: 834 839.

Vadlamudi, R.K., E. Weber, I. Ji, T.H. Ji, and L.A. Bulla Jr. 1995. Cloning and expression of a receptor for an insecticidal toxin of Bacillus thuringiensis. J. Biol. Chem. 270: 5490-5494.

Watabe, M., A. Nagafuchi, S. Tsukita, and M. Takeichi. 1994. Induction of polarized cell-cell association and retardation of growth by activation of the E-cadherin-catenin adhesion system in a dispersed carcinoma line. J. Cell Biol. 127: 247-256.

Wodarz, A., U. Hinz, M. Engelbert, and E. Knust. 1995. Expression of crumbs confers apical character on plasma membrane domains of ectodermal epithelia of Drosophila. Cell 82: $67-76$

Woods, D.F. and P.J. Bryant. 1993. Apical junctions and cell signaling in epithelia. J. Cell Sci. (Suppl.) 17: 171-181. 


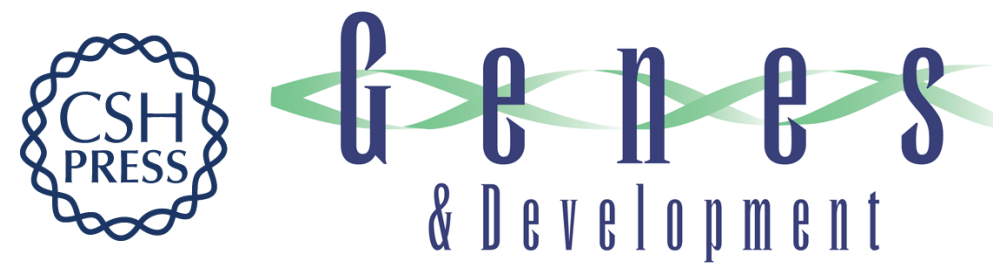

\section{Zygotic Drosophila E-cadherin expression is required for processes of dynamic epithelial cell rearrangement in the Drosophila embryo.}

T Uemura, H Oda, R Kraut, et al.

Genes Dev. 1996, 10:

Access the most recent version at doi:10.1101/gad.10.6.659

References This article cites 58 articles, 26 of which can be accessed free at: http://genesdev.cshlp.org/content/10/6/659.full.html\#ref-list-1

License

Email Alerting

Service

Receive free email alerts when new articles cite this article - sign up in the box at the top right corner of the article or click here.

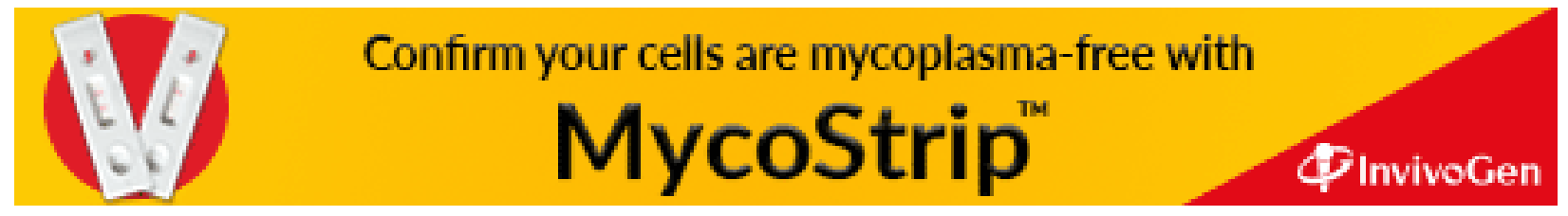

